\title{
Ateroskleroz yaygınlığı ile kolon kanseri gelişimi arasında ilişki var mi?
}

\author{
Is there a relationship between the severity of atherosclerosis and the development of colon cancer?
}

(D) Ahmet VURAL

Sağlık Bilimleri Üniversitesi, Fatih Sultan Mehmet Eğitim ve Araştırma Hastanesi, Radyoloji Kliniği, İstanbul

\begin{abstract}
Giriş ve Amaç: Kolorektal kanser ve ateroskleroz; erkek cinsiyet, Diabetes Mellitus, sigara içme ve obezite gibi yaygın risk faktörlerini paylaşmaktadır. Aterosklerozun kolorektal kanser riskini belirlemede önemini anlamak üzere kolorektal kanser ve abdominal aorta aterosklerozu arasındaki ilişkiyi araştırdık. Gereç ve Yöntem: Kolorektal kanser tanısı almış erkek hastaların tanı aldığı dönemdeki abdominal bilgisayarlı tomografi incelemeleri değerlendirilmiştir. Histopatolojik olarak kolorektal kanser tanısı konmasından 3 ay önce ve 3 ay sonraki dönem aralığında yapılmış olan abdominal bilgisayarlı tomografi incelemeleri olan 63 erkek hasta çalışmaya dahil edilmiştir. Ayrıca çeşitli nedenlerle abdominal bilgisayarlı tomografi incelemesi yapılmış 56 erkek denek kontrol grubu olarak değerlendirilmiştir. Abdominal bilgisayarlı tomografi incelemelerinde sagittal reformat görüntüler üzerinden, $L 2, L 3$ ve $L 4$ vertebralar seviyesinde, aorta ön ve arka duvarında izlenen ateroskleroz skorlandırılmıştır. Kolorektal kanseri bulunan ve kontrol grubu deneklerin abdominal aorta ateroskleroz skorları karşılaştırılmıştır. Bulgular: Kolorektal kanseri bulunan hasta grubunun yaş ortalaması $63.95 \pm 11.1$, kontrol grubu deneklerin yaş ortalaması $64.79 \pm 11.5$ idi. Kolorektal kanseri olanlarda abdominal aorta ateroskleroz skor ortalaması (5.44 \pm 3.7$)$, kontrol grubuna (3.86 \pm 2.6$)$ göre anlamlı düzeyde daha yüksekti ( $p$ $<0.05)$. Sonuç: Bu çalışmada, kolorektal kanseri bulunan olgularda abdominal aortada ateroskleroz şiddetinin kontrol grubuna kıyasla daha yüksek olduğu görüldü. Değişik nedenlerle yapılan abdominal bilgisayarlı tomografi incelemelerinde aorta ateroskleroz skorlamasının yapılması ile kolorektal kanser gelişim riski bakımından değerli bilgi edinilebileceğini düşünmekteyiz.
\end{abstract}

Anahtar kelimeler: Ateroskleroz, kolon kanseri, abdominal aorta
Background and Aims: Colorectal cancer and atherosclerosis share common risk factors, such as male gender, diabetes mellitus, smoking, and obesity. We investigated the relationship between colorectal cancer and atherosclerosis of the abdominal aorta to understand the importance of atherosclerosis in determining the risk of colorectal cancer. Materials and Methods: Sixty-three male patients with abdominal computed tomography examinations performed 3 months before and 3 months after the diagnosis were included in the study after being histopathologically diagnosed with colorectal cancer. In addition, 56 male subjects who had an abdominal computed tomography examination for various reasons comprised the control group. Atherosclerosis observed on the anterior and posterior wall of the aorta at the level of the $L 2, L 3$, and $L 4$ vertebra was scored on sagittal reformatted abdominal computed tomography images. The abdominal aortic atherosclerosis scores of the subjects with colorectal cancer and the control group were compared. Results: The mean age of the patient group with colorectal cancer was $63.95 \pm 11.1$ years, and the mean age of the control group was $64.79 \pm 11.5$ years. The mean abdominal aorta atherosclerosis score $(5.44 \pm 3.7)$ was significantly higher in the patients with colorectal cancer than in the control group $(3.86 \pm 2.6)(p<$ $0.05)$. Conclusion: Abdominal aorta atherosclerosis was more severe in patients with colorectal cancer than in the control group. Valuable information on the risk of colorectal cancer development can be obtained by scoring aortic atherosclerosis on abdominal computed tomography scans performed for various reasons.

Key words: Atherosclerosis, colon cancer, abdominal aorta

Yaş, sporadik kolorektal kanserlerde majör risk faktörüdür. 40 yaşından önce nadirdir. 40-50 yaşlar arasında anlamlı artış vardır. 50 yaşından sonraki her dekatta bu oranlar artmaya devam etmektedir $(4,5)$. Hem kolorektal kanserin hem de aterosklerozun erkek cinsiyet, diabetes mellitus, sigara içme ve obezite gibi ortak risk faktörlerine sahip olduğu bildirilmiştir (6). Bununla birlikte, bu iki hastalık arasındaki ilişki kapsamlı olarak araştııımamıştır.

Vural A. Is there a relationship between the severity of atherosclerosis and the development of colon cancer? The Turkish Journal of Academic Gastroenterology 2021;20:44-48. DOI: 10.17941/agd.931455

Geliş Tarihi: 28.01.2021 • Kabul Tarihi: 07.03.2021 
Kolorektal kanser ve koroner arter hastalığı (KAH) arasındaki ilişki üzerine yapılan az sayıda çalışma çelişkili sonuçlar bildirmektedir (6-12). Üç farklı çalışma kolorektal kanser ile $\mathrm{KAH}$ arasında anlamlı bir ilişki bulunmadığını belirtirken $(8,10)$, bir kaç çalışmada ise $\mathrm{KAH}$ ile kolorektal kanser ve adenomların birlikte görülmesi arasında anlamlı bir ilişki bulunmuştur $(7,9,13)$. Ancak bu çalışmaların çoğunda KAH için ya klinik bilgiler kullanılmış ya da efor testi, elektrokardiyografi (EKG) gibi indirekt veriler kullanılmıştır. Aterosklerozu koroner arterler dışında bir alandan, bilgisayarlı tomografi (BT) inceleme ile ayrıntılı olarak değerlendiren çalışma ise bulunmamaktadır.

Kolorektal adenokarsinomların çoğunun adenomlardan kaynaklandığı bilinmektedir. Çoğu $\mathrm{KAH}$ vakasına şiddetli ateroskleroz neden olur. Kolorektal kanser ve ateroskleroz, erken dönemde öncü lezyonlar ile tanımlanabilecek, görünüşte bağımsız, benzer patogeneze sahip süreçlerin geç belirtileridir (7). Bu nedenle, kolorektal adenom ve ateroskleroz için risk faktörlerinin tanımlanması, birbirleri ile ilişkinin ortaya konması hastalığın önlenmesi için önemlidir.

Bu çalışmanın amacı kolorektal kanser ile abdominal aortada ateroskleroz derecesi arasındaki ilişkiyi analiz etmektir. Ayrıca, demografik bulguların her iki durum ile ilişkisini inceleyerek risk faktörlerini ortaya koymak amaçlanmıştır.

\section{GEREÇ ve YÖNTEM}

\section{Denek Seçimi}

Ekim 2014'ten Haziran 2018'e kadar hastanemizde histopatolojik olarak kolorektal adenokarsinom tanısı alan hastalar incelenmiştir. Bu hastaların histopatolojik tanı tarihi esas alınarak bu tarihten 3 ay önceki ve 3 ay sonraki 6 aylık dönem taranmış ve bu tarih aralığında, operasyon öncesi abdominal BT incelemesi olan denekler çalışmaya dahil edilmiştir. Ateroskleroz ve kolorektal kanser gelişimi konusunda farklı etkenlerin sonuçları etkilemesini önlemek amacıyla 40 yaş altı ve 75 yaş üstü denekler, inflamatuvar bağırsak hastalığı bulunanlar, bağırsak rezeksiyonu olanlar, ateroskleroz ile ilişkili kronik hastalığı olanlar (Diyabetes Mellitus, hiperlipidemi, kronik böbrek hastalığı, hipertansiyon, kalp hastalığı) ve vücut kitle indeksleri yaşa uygun eğrilerde 95 persentil üzerinde olanlar çalışma dışında bırakıldı. Ayrıca abdominal aort anevrizması bulunan 2 hasta ile abdominal aorta grefi bulunan 1 hasta çalışma dışı bırakıldı. Sonuç olarak, toplam 167 kolorektal kanseri bulunan ve 111 kontrol grubu olarak değerlendirilen, abdominal BT incelemesi bulunan denekten; 63 kolorektal kanserli, 56 kontrol grubu denek çalışmaya dahil edildi. Çalışmaya alınan deneklerin dahil edilme ve hariç tutulma kriterlerine göre seçimini gösteren akım şeması
Şekil 1'de gösterilmiştir. Çalışma protokolü, Helsinki deklerasyonuna uygun olarak yapılmış olup kurumumuzun bilimsel çalışmalar ve etik kurulu tarafından onaylanmıştır (Fatih Sultan Mehmet Eğitim Araştırma Hastanesi-Klinik Araştırmalar Etik Kurulu-2020/161).

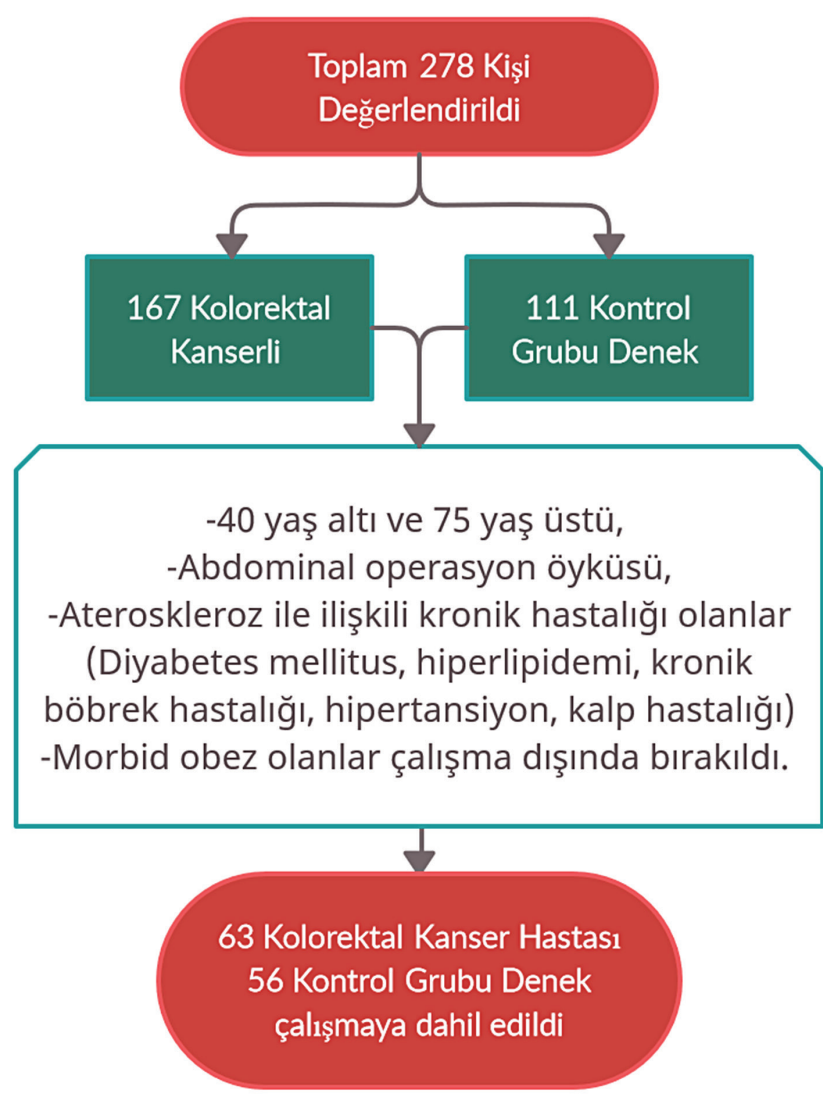

Şekil 1. Çalışmanın akış şeması.

\section{Bilgisayarlı Tomografi ile Aterosklerozun Değerlendirilmesi}

Incelemeler 128 kesitli (GE Healthcare Optima CT660, ABD) BT cihazı ile gerçekleştirildi. Sagittal reformat görüntüler incelenmiş olup abdominal aortanın L2-L4 vertebralar arasındaki seyri değerlendirilmiştir. L1-L2 intervertebral disk ile L2-L3 intervertebral disk arasındaki alan 1. seviye, L2-L3 intervertebral disk ile L3-L4 intervertebral disk arasındaki alan 2. seviye, L3-L4 intervertebral disk ile L4-L5 intervertebral disk arasındaki alan 3. seviye olarak ayrılmıştır. Her seviye için aortanın ön duvarı ve arka duvarı ateroskleroz bakımından ayrı ayrı puanlanmıştır. Seviyenin 1/3'ünden azında kalsifiye aterom plağı bulunması durumunda 1 puan, 1/3 ile 2/3'ü arasında aterom plağı bulunması durumunda 2 puan, 2/3'ünden daha fazla kısmı kaplayan aterom plağı varlığında 3 puan verilmiştir. Ön ve arka duvar puanları her seviye için toplanmış, ayrıca tüm seviyelerin puanları toplanarak abdominal aorta ateroskleroz skoru 
belirlenmiştir. Tüm çalışmalar 14 yıllık BT deneyimi olan bir radyolog tarafından analiz edildi (Resim 1). Ateroskleroz skrolamasına ilişkin örnekler Resim 2 üzerinde görülebilir.

\section{İstatistiksel Analiz}

Sürekli değişkenler ortalama olarak ifade edildi. Standart sapma (SD), kategorik değişkenler ise mutlak değerler ve yüzdeler olarak sunulmuştur. Sürekli değişkenler arasın-

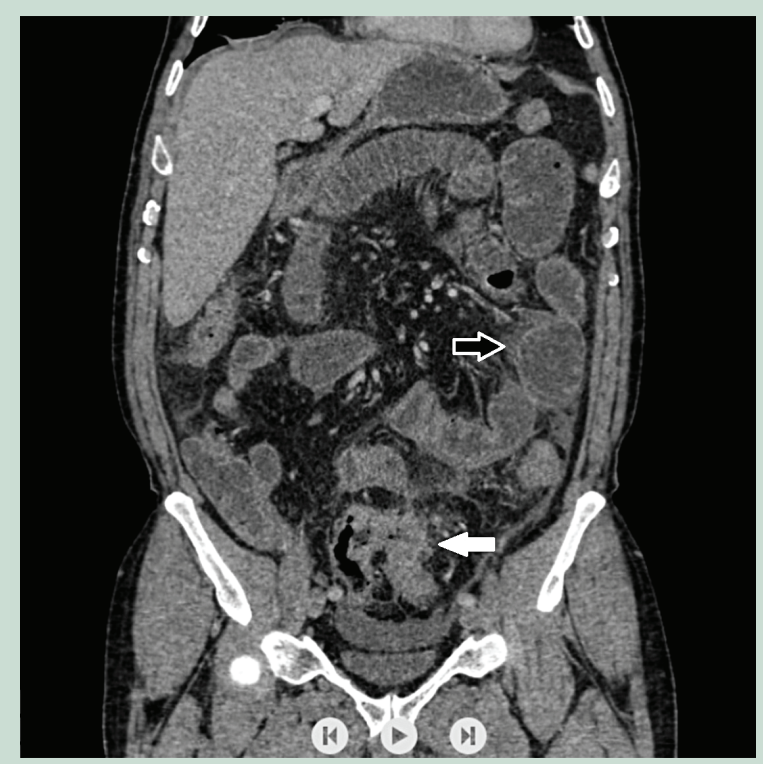

Resim 1. Sigmoid kolonda tümöre ait düzensiz duvar kaIınlaşması (içi dolu ok) ve proksimal barsak segmentlerinde dilatasyon (içi boş ok). daki farklar Student t-testi ile, kategorik değişken arasındaki farklar ki-kare testi ile analiz edildi. İstatistiksel analiz Statistical Package for the Social Science 22 (Windows için versiyon 22; SPSS, Türkiye) programı ile yapıldı. P değerinin $<0.05$ olması istatistiksel olarak anlamlı kabul edildi.

\section{BULGULAR}

Kolorektal kanser tanısı alan ve kontrol grubu hastaların demografik özellikleri Tablo 1'de karşılaştırılmıştır.

Kolorektal kanseri bulunan hasta grubunun yaş ortalaması $63.95 \pm 11.1$, kontrol grubu deneklerin yaş ortalaması $64.79 \pm 11.5$ idi. Çalışmaya dahil edilen 119 deneğin 47'si (\%39.5) günde en az 5 adet olmak üzere sigara içicisi idi. Kolorektal kanseri bulunan hasta grubunda sigara içicisi 26 (\%41), kontrol grubunda ise sigara içicisi sayısı 21 (\%38) idi. Kolorektal kanseri olanlar ile kontrol grubu denekler arasında sigara içiciliği bakımından istatistiksel olarak anlamlı farklılık yoktu $(p=0.678)$. Çalışmaya dahil edilen 119 deneğin vücut kitle indeksi (VKi) ortalaması $24.38 \pm 4.4$ idi. Kolorektal kanseri bulunan hasta grubunda VKI ortalaması $24.53 \pm 4.4$, kontrol grubunda ise VKI ortalaması $24 \pm 4.5$ idi. Kolorektal kanseri olanlar ile kontrol grubu denekler arasında VKI bakımından istatistiksel olarak anlamlı farklılık yoktu ( $p=0.647)$.

Kolorektal kanseri olanlarda abdominal aorta ateroskleroz skor ortalaması (5.44 \pm 3.7 ), kontrol grubuna (3.86 \pm 2.6) göre anlamlı düzeyde daha yüksekti $(p<0.05)$.

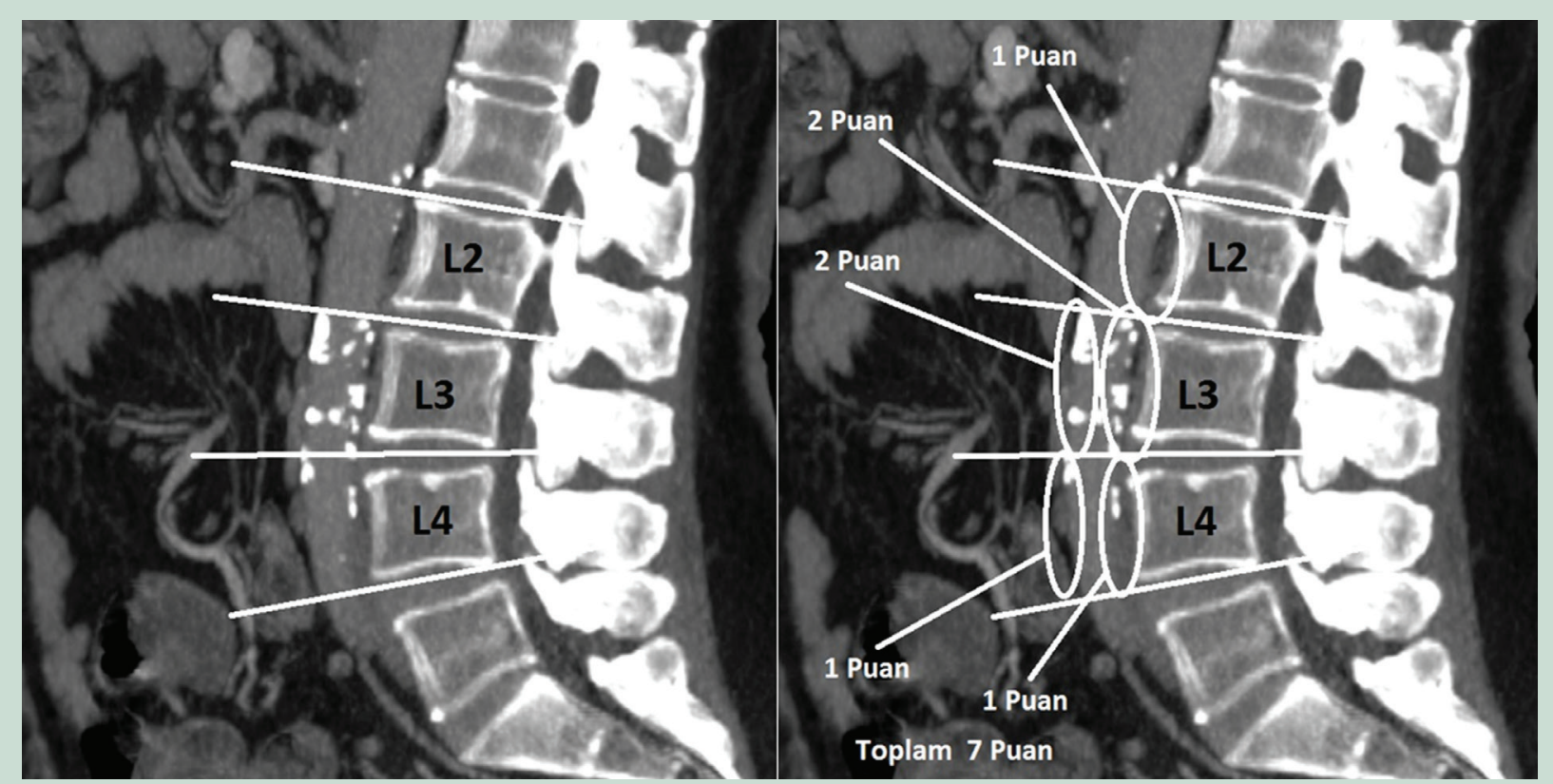

Resim 2. Sagittal reformat bilgisayarlı tomografi görüntüsünden abdominal aorta ateroskleroz skorunun hesaplanması. 
Tablo 1. Kolorektal kanser ve kontrol grubu temel bulguları

\begin{tabular}{lccc} 
& Kolorektal Kanser $(\mathbf{n}=\mathbf{6 3})$ & Kontrol Grubu $(\mathbf{n}=\mathbf{5 6})$ & P-value \\
\hline Yaş (yıl) & $63.95 \pm 11.1$ & $64.79 \pm 11.5$ & 0.689 \\
\hline Ateroskleroz skoru & $5.44 \pm 3.7$ & $3.86 \pm 2.6$ & 0.008 \\
\hline Sigara içimi (\%) & 41 & 38 & 0.678 \\
VKi $\left(\mathrm{m}^{2} / \mathrm{kg}\right)$ & $24.53 \pm 4.4$ & $24 \pm 4.5$ & 0.647
\end{tabular}

VKI: Vücut kitle indeksi.

\section{TARTISMA}

İnflamatuvar sürecin aterosklerozun merkezinde olduğu anlaşılmaktadır (14). Kolorektal karsinogenez ve yüksek C-reaktif protein (CRP) seviyeleri arasındaki ilişki dolaylı olarak kolorektal kanserin kronik inflamasyon ile bağlantılı olduğunu düşündürmektedir (15), nonsteroid antiinflamatuvar ilaçların (NSAii) düzenli kullanımının karsinogenezde tutarlı koruyucu etkisi olduğu (16) ve bazı proinflamatuvar sitokinlerin karsinogenezde önemli rol üstlendiği konusunda çalışmalar mevcuttur (17). Kolorektal adenomlarda, inflamasyon ile yakın ilişkisi bilinen siklooksijenaz-2 enziminin, makrofajlar ile birlikte stromal hücrelerde bulunduğu gösterilmiştir (18).

Ayrıca, ateroskleroz ve kolorektal karsinogenezde ortak olan moleküler mekanizmalar ortaya çıkarılmıştır. Örneğin, proinflamatuvar sitokin olan makrofaj migrasyon inhibitör faktörün (MIF) aterogenez (19) ve kolorektal karsinogenezin (20) ilk aşamalarında rol oynadığı gösterilmiştir.

Aterosklerotik hastalık ve kolorektal kanser arasındaki ilişki ağırlıklı olarak Asya kaynaklı çalışmalarda ortaya konulmuştur. Asya dışı popülasyonlarda daha ileri epidemiyolojik çalışmalar yapılmalı, ateroskleroz ve kolorektal karsinogenez konusunda kronik inflamasyonun rolünün daha iyi anlaşılması gerekmektedir. Ayrıca obezite gibi proinflamatuvar durumlarla bağlantının aydınlatılması (21), risk faktörleri olarak CRP ve serum sitokin seviyeleri gibi inflamasyon biyobelirteçlerinin rolünün araştırılması gerekmektedir. Belki de inflamasyona yönelik tedavi, kanser önleme ve vasküler profilaksi konusunda birlikte kullanılabilecek, değerli bir seçenek olabilecektir (22).

Bu çalışmada, kolorektal kanser hastaları ile kontrol grubu deneklerde abdominal BT ile saptanan aorta ateroskleroz skoru arasındaki ilişki araştırıldı. Kolorektal kanseri bulunan hastalarda kontrol grubuna göre daha yüksek abdominal aorta ateroskleroz skoru olduğunu bulduk.

Hong Kong'da yapılan bir çalışmada, kolonoskopi ile belirlenmiş kolon lezyonları varlığı ile koroner anjiyografi ile saptanmış KAH varlığı arasında bir ilişkinin bulunduğu raporlanmıştır (6). Sağlıklı kontrol grubu hastalara invaziv koroner anjiyografi uygulama konusundaki sınırlamalar nedeni ile BT anjiyografi (BTA) ile koroner arterlerin değerlendirildiği, kolorektal adenom ve polip varlığı ile ilişkisinin araştırıldığı bir başka çalışmada, koroner ateroskleroz ile kolorektal adenom varlığı arasında anlamlı bir ilişki bulunmuştur (23). Bu çalışmada BTA'nın koroner arterin subklinik aterosklerozunu tespit etmek ve olası kardiyovasküler sorunların önüne geçebilmek için yararlı bir araç olabileceği bildirilmektedir.

Çalışmamızda verileri, daha önceki çalışmaların aksine koroner arter aterosklerozu değil abdominal aorta aterosklerozu ile değerlendirdik. Ayrıca Chan ve ark.'nın anlamlı darlık varlığı ya da yokluğu (6) ya da Yang ve ark.'nın koroner arterlerin normal, hafif darlık (\%50 altı) ve ileri darlık (\%50 üstü) şeklinde yaptıkları (23) sınırlı sınıflamaların aksine abdominal aorta üzerinden L2-L4 arası geniş bir bölgede, ayrıntılı bir skorlama ile ateroskleroz değerlendirmesi yaptık. Bu skorlama yöntemi Kauppila ve ark. (24) tarafından tanımlanan L1-L4 vertebralar arası uyguladıkları abdominal aorta ateroskleroz skorlamasının modifiye edilmiş halidir. Ateroskleroz ve kolorektal kanser gelişimi konusunda etkili olabilecek erken ve geç yaş aralıkları, inflamatuvar bağırsak hastalığı öyküsü, Diyabetes Mellitus, hiperlipidemi, kronik böbrek hastalığı, hipertansiyon gibi kronik hastalıklara sahip olanlar ile morbid obez denekler çalışma dışı bırakılarak abdominal aortada aterosklerozun kolorektal kanser için bağımsız bir risk faktörü olduğunu gördük. Sonuçlarımız aterosklerozun kolorektal kanser ile yüksek oranda ilişkili olduğunu göstermektedir. Bu iki hastalığın eşzamanlı gelişimi konusunda olası mekanizmaları belirlemek için daha fazla çalışmaya intiyaç vardır.

Çalışmamızın bazı sınırlılıkları vardı. Birincisi, BT inceleme ile yapılan kesitsel bir çalışmaydı ve ortaya konan ilişkinin nedensellik değerlendirmesi yapılamadı. İkincisi, değerlendirmeyi etkilememesi için risk faktörlerinin bir kısmını dışladık ancak, deneklerin alkol tüketimi, aspirin ve diğer NSAil'lar veya antilpidemik ilaçların kullanımı göz önüne alınmamıştır. Ayrıca diyet değişkenleri değerlendirilemiş- 
tir. Çalışmamızda kontrol grubu olarak alınan denekler genel olarak böbrek taşı, nonspesifik karın ağrısı ya da travma sonrası abdominal BT taraması yapılan kişilerden seçildi. Genel popülasyonda abdominal aortada aterosklerozun prevalansını değerlendirmek zordur, çünkü sağlıklı insanların tümüne tarama amaçlı abdominal BT inceleme yapmak mümkün değildir. Bu çalışmanın denekleri şikayetlerini önemseyerek sağlık merkezini ziyaret eden ve abdominal BT uygulanan bireylerden alınmıştır. Böylece sağlık durumları konusunda daha fazla endişe eden ve genel nüfusa göre daha bilinçli ve beslenme durumları daha iyi olan bireyler olma intimalleri mevcuttur. Dolayısıyla kontrol grubu denekler ile kolorektal kanseri bulunan hastaların beslenme durumlarının tam olarak karşılaştıılamaması çalışmanın sınıllamalarından biri olarak kabul edilebilir. Bu değişkenler kolorektal kanser ve ateroskleroz riskinde önemli bir rol oynayabilir. Kolorektal kanser ve ateroskleroz birlikteliği konusunda diğer risk

\section{KAYNAKLAR}

1. American Cancer Society. Colorectal Cancer Facts \& Figures 20202022. Atlanta, Ga: American Cancer Society; 2020.

2. Yiğit T. Kolonoskopi deneyimlerimiz: Ardışık 983 hastanın irdelenmesi. Kolon Rektum Hast Derg 2007;17:154-9.

3. Tamer A, Korkut E, Korkmaz U, Akcan Y. Alt gastrointestinal endoskopi sonuçlarımız: Düzce bölgesi. The Medical Journal of Kocatepe 2005;6:29-31.

4. Heitman SJ, Ronksley PE, Hilsden RJ, et al. Prevalence of adenomas and colorectal cancer in average risk individuals: a systematic review and meta-analysis. Clin Gastroenterol Hepatol 2009;7:1272-8.

5. Eddy DM. Screening for colorectal cancer. Ann Intern Med 1990;113:373-84.

6. Chan $\mathrm{AO}$, Jim MH, Lam KF, et al. Prevalence of colorectal neoplasm among patients with newly diagnosed coronary artery disease. JAMA 2007;298:1412-9.

7. Correa P, Strong JP, Johnson WD, et al. Atherosclerosis and polyps of the colon. Quantification of precursors of coronary heart disease and colon cancer. J Chronic Dis 1982;35:313-20.

8. Kune GA, Kune S, Watson LF. Colorectal cancer risk, chronic illnesses, operations, and medications: case control results from the Melbourne Colorectal Cancer Study. Cancer Res 1988;48:4399-404.

9. Neugut AI, Jacobson JS, Sherif G, et al. Coronary artery disease and colorectal neoplasia. Dis. Colon Rectum. 1995;38:873-7.

10. Neugut Al, Rosenberg DJ, Ahsan H, et al. Association between coronary heart disease and cancers of the breast, prostate, and colon. Cancer Epidemiol Biomarkers Prev 1998;7:869-73.

11. Chan AO, Lam KF, Tong T, et al. Coexistence between colorectal cancer/adenoma and coronary artery disease: results from 1382 patients. Aliment Pharmacol Ther 2006;24:535-9.

12. Liao KF, Lai HC, Lai SW, Cheng KC, Lin CH. Association between rectosigmoid adenomas and cardiovascular risk factors: a hospital-based, cross-sectional study. Ann Acad Med Singap 2009;38:630-6. faktörlerinin de dahil edileceği çalışmalara intiyaç vardır.

Özetle, kolorektal kanseri bulunan erkek hastalar ile sağlık kontrollerinin bir parçası olarak abdominal BT incelemesi yapılan deneklerin değerlendirildiği çalışmamızda, kolorektal kanseri olanlarda kontrol grubuna göre abdominal aortada ateroskleroz skoru anlamlı olarak yüksek bulunmuştur. Abdominal aorta ateroskleroz skorunun, kolorektal kanser için bağımsız bir risk göstergesi olarak kullanılabilmesi mümkün olabilir.

Etik Kurul Onayı: Fatih Sultan Mehmet Eğitim Araştırma Hastanesi, Klinik Araştırmalar Etik Kurulunun 2020/161 kararı ile etik kurul onayı alınmıştır.

Çıkar Çatışması: Yazarlar herhangi bir çıkar çatışması beyan etmemişlerdir.

Finansal Destek: Yazarlar finansal destek beyan etmemişlerdir.
13. Stemmermann GN, Heilbrun LK, Nomura A, Yano K, Hayashi T. Adenomatous polyps and atherosclerosis: an autopsy study of Japanese men in Hawaii. Int J Cancer 1986;38:789-94.

14. Libby P: Inflammation in atherosclerosis. Nature 2002;420:868-74.

15. Tsilidis KK, Branchini C, Guallar E, et al. C-reactive protein and colorectal cancer risk: a systematic review of prospective studies. Int J Cancer 2008;123:1133-40.

16. Arber N, Levin B: Chemoprevention of colorectal neoplasia: the potential for personalized medicine. Gastroenterology 2008; 134:1224-37.

17. Robinson SC, Coussens LM. Soluble mediators of inflammation during tumor development. Adv Cancer Res 2005;93:159-87.

18. Chapple KS, Cartwright EJ, Hawcroft G, et al. Localisation of cyclooxygenase-2 in human sporadic colorectal adenomas. Am J Pathol 2000;156:545-53.

19. Morand EF, Leech M, Bernhagen J. MIF: a new cytokine link between rheumatoid arthritis and atherosclerosis. Nat Rev Drug Discov 2006;5:399-410.

20. Wilson JM, Coletta PL, Cuthbert RJ, et al. Macrophage migration inhibitory factor promotes intestinal tumorigenesis. Gastroenterology 2005;129:1485-503.

21. Giovannucci E, Michaud D. The role of obesity and related metabolic disturbances in cancers of the colon, prostate, and pancreas. Gastroenterology 2007;132:2208-25.

22. Hull M, Kant P. Atherosclerosis and colorectal carcinogenesis: shared risk factors or common pathogenesis? Digestion 2010;81:16-7.

23. Yang SY, Kim YS, Chung SJ, et al. Association between colorectal adenoma and coronary atherosclerosis detected by CT coronary angiography in Korean men; a cross-sectional study. J Gastroenterol Hepatol 2010;25:1795-9.

24. Kauppila LI, Polak JF, Cupples LA, et al. New indices to classify location, severity and progression of calcific lesions in the abdominal aorta: a 25-year follow-up study. Atherosclerosis 1997;132:245-50. 